\title{
Satellite DNA Libraries and Centromere Evolution
}

\author{
Đurđica Ugarković*
}

Department of Molecular Biology, Ruđer Bošković Institute, Bijenička 54, P.O. Box 180, HR-10002 Zagreb, Croatia

\begin{abstract}
Related species share a pool of satellite DNA sequences known as a satellite DNA library. Such sequences may persist in the genome for long evolutionary time at latent locations and can be amplified in any species. This leads to rapid turnover of satellite DNA composition which is characteristic for centromere evolution. The «library» hypothesis however does not predict whether any of the sequences can be amplified, and subsequently confer a centromere role. Based on structural and evolutionary studies it is proposed that satellite DNAs are highly adapted sequences whose evolution has proceeded through the combined action of natural selection and molecular drive. Their recruitment to a satellite library and retention within the genome could be related to some structural characteristics which enable them to be extended into a functional centromere array. A newly formed array could replace the previous centromere if it has some selective advantage in transmission at meiosis due to particular satellite sequence features and/or high homogeneity.
\end{abstract}

Keywords: Satellite DNA, centromere, kinetochore, heterochromatin.

\section{CENTROMERE AND SATELLITE DNA}

The centromere is known as a locus required for accurate chromosome inheritance, visible as the primary constriction on metaphase chromosomes. Centromeric chromatin contains histone modification patterns which are distinct from the flanking heterochromatin and provides the structural foundation for the establishment of kinetochore [1]. The kinetochore assembles onto the centromere in the form of a large multiprotein complex that links the chromosome to the microtubules of the mitotic spindle. It directs chromosome movement during mitosis and meiosis and is critical in sensing completion of metaphase before allowing anaphase to begin [2]. Whereas the proteins responsible for forming the kinetochore are conserved throughout the species, the DNA sequences found at centromeres are highly divergent [3]. The common feature of centromeres across the wide species range which includes Arabidopsis thaliana, rice, maize, Drosophila melanogaster and humans, is the presence of satellite DNA as their predominant component [4-8]. In the case of human chromosomes, the main centromeric component is alpha satellite DNA. It has been shown that alpha satellite DNA is not absolutely necessary for centromere formation since in its absence euchromatic DNA is capable of being activated to form a "neo-centromere" [9]. However in the presence of alpha satellite, the centromere is always formed on the alpha satellite array [10]. Therefore, alpha satellite and probably other satellite DNAs are considered to be preferred substrates for centromere establishment. In addition, transcripts of alpha satellite DNAs have been shown to be a functional component of the kinetochore participating in recruitment of kinetochore proteins [11]. All these data point to an important role for satellite DNA in centromere/kinetochore establishment and function. In addition, new findings related to evolutionary constraints on satellite DNAs can shed more light on the evolution of centromere.

*Address correspondence to this author at the Department of Molecular Biology, Ruđer Bošković Institute, Bijenička 54, P.O. Box 180, HR-10002 Zagreb, Croatia; Tel: +385 14561197; Fax: +385 14561177 ;

E-mail: ugarkov@.irb.hr

\section{SATELLITE DNA LIBRARY}

According to the «library» hypothesis centromeric satellite DNAs may persist in the genome at latent locations for long evolutionary time forming a collection or library of satellite sequences shared among related lineages [12]. The amount of satellite DNAs in a single centromere can be increased or reduced dramatically in a short time frame. Such rapid turnover characteristic for centromere evolution can be explained by differential amplification of satellite DNAs from the library in any species [13]. The first experimental demonstration of a satellite DNA library is found in the insect genus Palorus (Coleoptera) where all examined species posses a common collection of centromeric satellite DNAs [14]. A different single satellite is significantly amplified in each of the different species resulting in species specific satellite DNA profiles. The existence of satellite libraries is supported for different groups of species including plants, nematodes, insects and mammals, as well as their preferential localization within pericentromeric and centromeric regions [15-21]. In the marsupial genus Macropus three satellite DNAs present within the library are involved in the creation of centromeric arrays in nine examined species [22]. Each species however has experienced different expansion and contraction of individual satellites. In Bovini, six related centromeric satellite DNAs are shared among species fluctuating considerably in relative amounts [23].

Different satellite DNAs that coexist in the same species in the form of a library can vary significantly in their sequence homogeneity and are considered as independent evolutionary units. In addition, each satellite DNA can exist in the form of different, usually chromosome specific satellite subfamilies [reviewed in 13]. All primate species share alpha satellite DNA which in the form of different subfamilies represents the major component of all centromeres [24]. Alpha satellite is composed of two basic types of repeat units: a $171 \mathrm{bp}$ monomer and higher order repeats (HOR). Higher order repeats have complex repeat units composed of up to 30 diverged $171 \mathrm{bp}$ monomers [25]. In the genomes of lower primates monomeric alpha satellite repeats prevail and comprise long centromeric arrays. Monomeric repeats character- 
istic for low primates lack a $17 \mathrm{bp}$ motif known as the CENP-B box which represents a binding site for centromere protein B (CENP-B). In higher primates such as the great ape and humans, higher order repeats are amplified and are characterized by the presence of CENP-B binding sites. As shown for the human $\mathrm{X}$ chromosome higher order repeats are major constituents of functional centromere while alpha satellite DNA in the form of monomers remains in pericentromeric regions [26]. It has been proposed that higher order repeats appeared relatively recently in the primate lineage, coinciding with the great ape evolution [8, 26]. However, simple higher order repeats in the form of dimers are common to all lower primates, as revealed by analysis of wholegenome shotgun sequence data [27]. In addition, CENP-B protein has been found in lower primates, dispersed in the outer regions of centromeres, out of the kinetochore as well as throughout the nuclei $[28,29]$. The presence of the CENP$\mathrm{B}$ protein suggests the existence of latent higher order repeats having a CENP-B box in the genomes of lower primates. Such alpha satellite distributional pattern in lower and higher primates is well explained by library dynamics. It can be proposed that alpha satellite DNA in the form of monomers as well as simple higher order repeats existed very early in primates. Evolution of centromeres within lower primates has proceeded mostly through expansion of sequences already present within the common primate library. These sequences have been extensively exchanged and homogenized among chromosome due to genetic turnover mechanisms of unequal crossingover and gene conversion which are involved in the process of molecular drive [30]. In higher primates however intrachromosomal homogenization has predominated relative to interchromosomal exchange due to different rate and/or effectiveness of genomic turnover mechanisms. This results in the generation of new, chromosome specific higher order repeats and chromosome specific subfamilies. Such newly acquired and fast evolving complex HORs have been subsequently expanded into centromeric arrays in all great ape species as well as in humans [26].

\section{EVOLUTIONARY CONSTRAINTS ON SATELLITE DNAS}

Based on the structural and evolutionary studies of diverse satellite DNAs it can be proposed that satellite sequences within a library are highly adapted and relatively conserved in the sense that they can tolerate limited sequence change. In some instances such as four satellite DNAs of the coleopteran insect genus Palorus, the sequences remain completely frozen for long evolutionary periods of up to 60 million years [31, 32]. Remarkable sequence conservation is also characteristic of human alpha satellite DNA, which has been detected as a rare, highly conserved repeat in evolutionary distant species such as chicken and zebrafish [33]. Most of the known satellites exhibit sequence change which seems to be constrained by selection in order to preserve some structural characteristics [reviewed in 34]. In addition to selection, the rate of sequence change depends on mutation rate, rates of recombinational processes that spread mutations horizontally through the repetitive family as well as on the rate of fixation within a population [30]. Satellite sequences generally evolve in two manners: gradually by accumulating mostly single point mutations and saltatory due to larger rearrangements induced by recombination and nonMendelian exchanges occurring in the genome [13, 35]. Due to such complex evolution, the rate of divergence of particular satellite DNA sequence is not uniform between species and often not within a species, varying between chromosomes [36, 37]. Evolutionary rate can also be significantly different for related satellite DNAs present in parallel within the pair of species. Comparison between human and orthologous chimpanzee chromosomes reveals different evolutionary rates for the two types of alpha-satellite DNA: higherorder repeats located within the centromere evolve much faster than monomers at the pericentromeric location [38].

In order to be retained in the genome and to become a member of the library satellite sequences seem to have acquired certain structural features. Some of these characteristics might include an ability to bind necessary chromatin components such as diverse kinetochore proteins. In humans, centromeric proteins $\mathrm{A}, \mathrm{B}$ and $\mathrm{C}$ (CENP-A, CENP-B, CENP-C) bind alpha satellite DNA. While CENP-B specifically recognizes 17 bp motif in alpha satellite DNA known as the CENP-B box, CENP-A and CENP-C do not exhibit such sequence specificity. CENP-A corresponds to a centromere-specific histone variant $\mathrm{CenH} 3$ which replaces $\mathrm{H} 3$ in centromeric nucleosomes. $\mathrm{CenH} 3$ has been shown to be subjected to adaptive evolution and its coevolution with centromeric DNA has been proposed [39]. Besides binding DNA, CENP-C is also an RNA-associating protein that binds transcripts of alpha satellite DNA. It has been revealed that long, single stranded alpha satellite DNA transcripts encompassing a few satellite monomers are functional components of the human kinetochore. They are required for the association of kinetochore proteins CENP-C1 and INCENP in the human interphase nucleolus as well as at the centromere [11]. It is possible that constrains on alpha satellite RNA secondary and/or tertiary structure exist in order to preserve its ability to bind kinetochore proteins such as CENP-C1.

The effect of selection on satellite DNA sequence is probably reflected in the non-random distribution of variability along satellite monomers, resulting in constant and variable regions. Such a distribution is characteristic of many satellites including the centromeric satellite of Arabidopsis thaliana and human alpha satellite DNA [40].

A non-random pattern of variability indicates possible functional constraints on satellite DNA sequence that might be related to specific protein-binding sites. Selective constraints on satellite sequence are probably not only related to their interaction with specific proteins but also to their role in controlling gene expression. Transcription of satellite DNA seems to be a general phenomenon as well as the processing of transcripts into different regulatory RNAs (Fig. 1; reviewed in [34]).

Despite the extreme sequence divergence of satellite DNAs most of them exhibits some common structural characteristics such as clustering of $\mathrm{A}$ or $\mathrm{T}$ and regular phasing of $A$ or $T \geq 3$ tracts, as well as dyad structures [41]. Periodic distribution of AT tracts usually leads to curvature of the DNA helix axis, which is characteristic of approximately $50 \%$ of satellite DNAs [42]. As a result of this curvature, a superhelical tertiary structure is formed that is thought to be important for the tight packing of DNA and proteins in heterochromatin [42, 43]. In general, it can be concluded that 


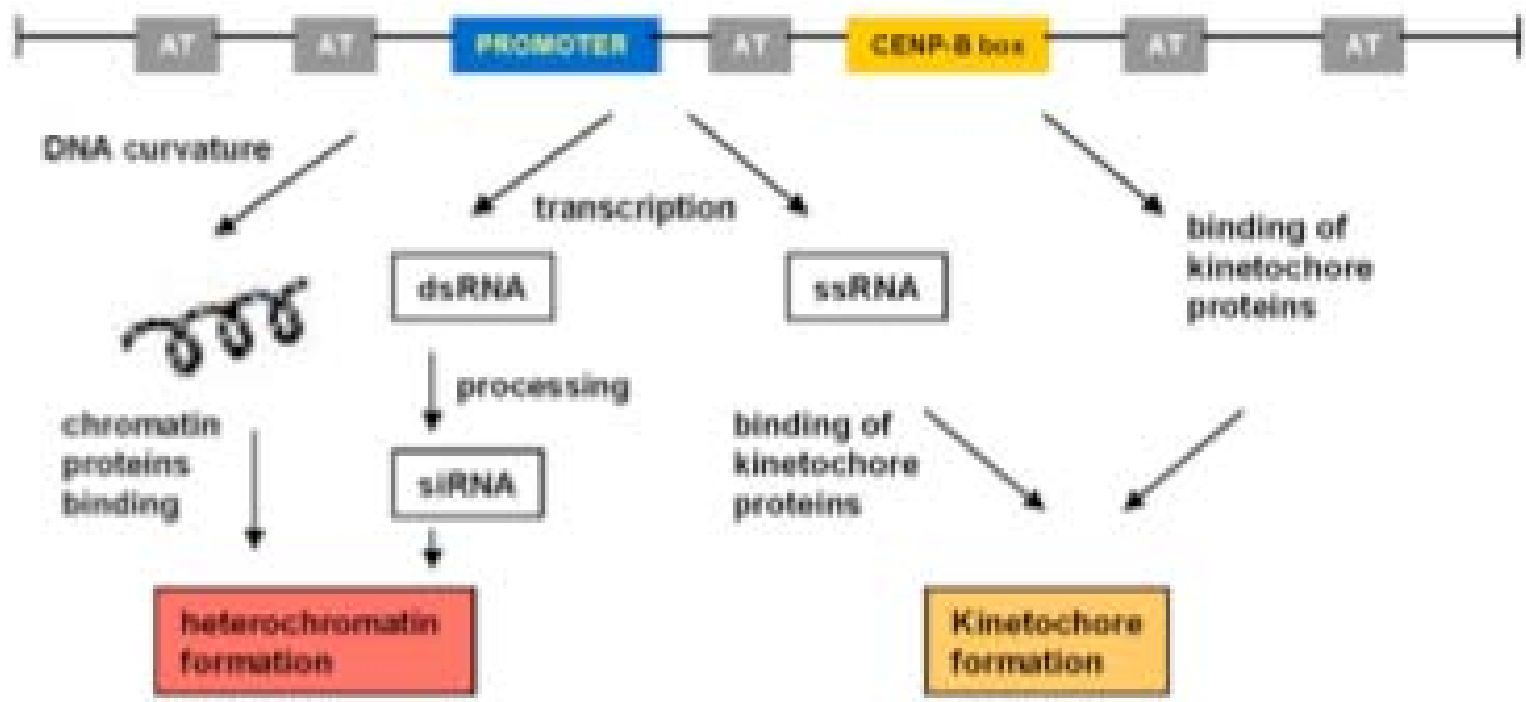

Fig. (1). Evolutionary constraints on centromeric satellite DNAs. Structural requirements posed on satellite DNAs which enable them to be retained in the genome as members of satellite library might include periodic clusters of A+Ts, binding sites for centromeric proteins such as CENP-B box, or promoter elements necessary for active transcription. Periodic distribution of AT tracts leads to curvature of the DNA helix axis and formation of superhelical tertiary structure thought to be important for heterochromatin establishment. Transcription of satellite DNAs proceeds either in the form of double-stranded RNA (dsRNA) or single-stranded RNA (ssRNA). Long, ssRNAs are required for the association of kinetochore proteins while dsRNA is processed into small interfering RNAs (siRNAs) that participate in heterochromatin formation. Constraints on satellite RNA secondary and/or tertiary structure could exist in order to preserve its ability to bind kinetochore proteins.

there are some structural requirements posed on satellite DNAs which enable them to become potentially functional and to be retained in the genome as members of the satellite library (Fig. 1).

\section{CENTROMERE EVOLUTION}

Taking into account the existence of satellite libraries and the relative conservation of satellite sequences as well as their structural features it can be proposed that the evolution of the centromere does not proceed through «de novo» adoption of «new», previously noncentromeric sequences which are repeatedly introduced into the genome as predicted by centromere drive [44]. On the contrary, the centromere is formed from already adapted sequences that reside within the satellite library and have certain structural characteristics that enable these sequences to confer a centromeric role (Fig. 2). The content of the library is constantly evolving, new sequences can be generated and added into the library such is the case of alpha satellite complex HORs which appear later in the evolution of primate lineage [25]. On the other hand, some «old» centromeric satellite repeats can be lost in particular lineages as shown for centromeric satellites in species of grass [45]. Removal of centromeric satellites from the library is probably a stochastic process mediated by mechanisms of unequal crossing over and illegitimate recombination $[46,47]$.

Satellite sequences from the library can undergo recurrent repeat copy number expansion and contraction in divergent lineages. This amplification from the library seems to be random and does not correlate with phylogeny of the species as shown for the insect genus Pimelia, the marsupial genus Macropus and grass species [22, 45, 48]. The same satellite sequences can undergo convergent expansion on all chromosomes in different lineages. Although the evolution of centromeric satellite DNA composition does not follow species phylogeny it parallels chromosome evolution in some karyotypically divergent lineages [22, 49]. The rate of turnover of satellite DNAs differs among species ranging from abrupt-saltatory amplification and replacement of satellites in relatively short periods of time, through gradual changes in satellite DNA profiles, while in some instances no apparent change occurs for long evolutionary time [48]. Amplification of a sequence from the library could occur due to unequal crossingover or duplicative transposition $[47,50]$ while the spreading and fixation in population is influenced by stochastic process of molecular drive [30]. The discovery of human extrachromosomal elements originating from satellite DNA arrays in cultured human cells indicates the possible existence of other amplification mechanisms based on extrachromosomal rolling-circle replication [51]. It has been proposed that satellite sequences excised from their chromosomal loci via intrastrand recombination could be amplified in this way, followed by reintegration of tandem arrays into the genome [52]. Mechanistic processes inherent to chromosome fusion and translocation have been also supposed to be responsible for contraction and expansion of satellite DNA arrays [22].

A newly amplified satellite array can replace the previous centromere and prevail in the population if it has some selective advantage relative to the «old» centromere e.g. transmission advantage at meiosis due to some sequence characteristic of newly amplified satellite DNA or just due to the higher homogeneity of newly amplified array relative to the «old» one. Based on the structure of the human X chromosome centromere it can be proposed that high homogeneity and integrity of newly expanded satellite arrays might represent an additional requirement imposed on the centromere. In addition, it seems that a newly expanded array has to be of 
satellite DNA

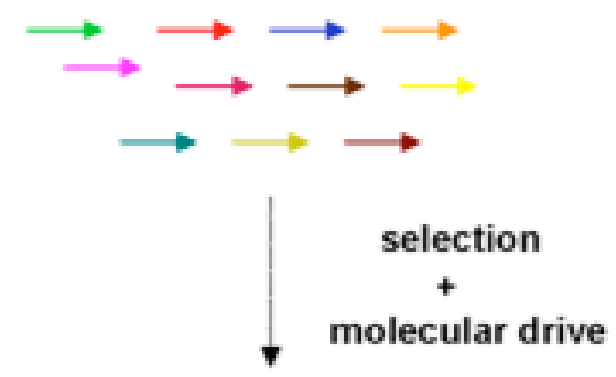

\section{Satellite DNA library}

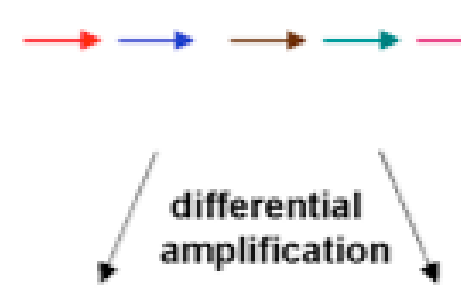

\section{centromere}

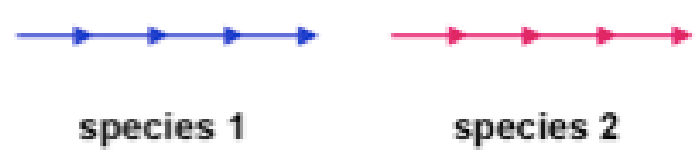

Fig. (2). Model of satellite DNA evolution and centromere formation. A bulk of satellite sequences dispersed in the genome is subjected to influence of natural selection and molecular drive. Those satellites possessing certain structural features which enable them to become functional are retained in the genome in the form of satellite DNA library. Differential amplification of centromeric satellite DNAs from the library in two related species can lead to formation of a "new" centromere array which can replace the previous centromere in each species. Differential amplification which is probably due to unequal crossingover or duplicative transposition, is also responsible for the rapid turnover of satellite DNA content and centromere evolution.

certain length in order to become a preferred substrate for centromere formation. The repetitiveness of satellite DNA has been proposed to be important for orderly packing of nucleosomes [53] and nucleosome crystallization on reverse repeats of alpha satellite DNA support this assumption [54, 55]. Centromeric nucleosomes are specific not only by the presence of $\mathrm{CenH} 3$, but by their internal organization. They are organized as a heterotypic tetramer composed of one molecule each of CenH3, H2A, H2B and H4, different from the octamer found in bulk nucleosomes [56]. It can be suggested that such nucleosome tetramers distributed orderly on homogenous and uninterrupted satellite arrays represent an accessible surface for kinetochore assembly.

Due to the constant dynamics of repetitive DNA, centromeric satellite DNA array can be expanded affecting kinetochore size, which could further influence normal chromosome segregation [44]. It is proposed that centromere can be expanded by sequences which might be variants of native centromeric array, by different sequences transposed from other chromosome or by completely novel satellite DNA. Mutations which reduce sequence specificity of key kinetochore proteins such as $\mathrm{CenH} 3$ or CENP-C are suggested to loose the influence of DNA on kinetochore size and help to restore epigenetic inheritance and Mendelian segregation [44]. Observed accelerated evolution of CenH3 and CENP-C speaks in favour of this assumption. The model of centromere evolution presented here however suggests that the preferential substrate for centromere expansion are satellite DNAs that in the form of library reside in centromeric regions and are already adapted to confer centromere role.

\section{CONCLUSION}

Numerous satellite DNAs are present in parallel within genomes of related species forming a so called satellite DNA library. Satellite DNAs may significantly differ in copy number within and between species but preserve location within pericentromeric and centromeric regions and reside within genomes for long evolutionary periods. Some of the satellites are extended into arrays which comprise a functional centromere. Random amplification as well as deletion of satellite DNA sequences from the library which does not correlate with phylogeny of the species is characteristic for satellite DNA evolution. It also correlates with rapid sequence turnover which is characteristic for centromere evolution. It is proposed that satellite DNAs have been selected and recruited to a library based on particular sequence features which enable them to confer a centromere role. The centromere is therefore formed from highly adapted satellite sequences recycled from the library and not from de novo introduced sequences. A newly expanded satellite array can replace the previous centromere if it has advantage in meiosis, probably due to higher homogeneity and integrity of the array or due to some particular sequence features important for binding of centromere proteins.

\section{ACKNOWLEDGEMENTS}

I am grateful to Mary Sopta for critical reading of the manuscript. This work was supported by grant 00982604 from the Croatian Ministry of Science and EU FP6 Marie Curie Transfer of Knowledge Grant MTKD-CT-2006042248 . 


\section{REFERENCES}

[1] Dobie, K.W.; Hari, K.L.; Maggert, K.A.; Karpen, G.H. Centromere proteins and chromosome inheritance: a complex affair. Curr. Opin. Genes Dev., 1999, 9: 206-217.

[2] Nasmyth, K. Segregating sister genomes: the molecular biology of chromosome separation. Science, 2002, 288: 559-565.

[3] Malik, H.S.; Henikoff, S. Conflict begets complexity: the evolution of centromeres. Curr. Opin. Genet. Dev., 2002, 12: 711-718.

[4] Kumekawa, N.; Hosouchi, T.; Tsuruoka, H.; Kotani, H. The size and sequence organization of the centromeric region of Arabidopsis thaliana chromosome 4. DNA Res., 2001, 8: 285-290.

[5] Zhang, Y.; Huang, Y.C.; Zhang, L.; Li, Y.; Lu, T.T.; Lu, Y.Q.; Feng, Q.; Zhao, Q.; Cheng, Z.K.; Xue, Y.B.; Wing, R.A.; Han B. Structural features of the rice chromosome 4 centromere. Nucleic Acids Res., 2004, 32: 2023-2030.

[6] Jin, W.; Melo, J.R.; Nagaki, K.; Talbert, P.B.; Henikoff, S.; Dawe, R.K.; Jiang, J. Maize centromeres: organization and functional adaptation in the genetic background of oat. Plant Cell, 2004, 16: 571-581.

[7] Sun, X.; Le, H.D.; Janice M. Wahlstrom, J.M., Karpen, G.H. Sequence analysis of a functional Drosophila centromere. Genome Res., 2003, 13: 182-94.

[8] Schueler, M.G.; Higgins, A.W.; Rudd, M.K.; Gustashaw, K.; Willard, H.F. Genomic and genetic definition of a functional human centromere. Science, 2001, 294: 109-115.

[9] Amor, D.J.; Choo, K.H. Neocentromeres: role in human disease, evolution and centromere studies. Am. J. Hum. Genet., 2002, 71: 695-714.

[10] Grimes, B.R.; Rhoades, A.A.; Willard, H.F. Alpha-satellite DNA and vector composition influence rates of human artificial chromosome formation. Mol. Ther., 2002, 5: 798-805.

[11] Wong, L.H.; Brettingham-Moore, K.H.; Chan, L.; Quach, J.M.; Anderson, M.A.; Northrop, E.L.; Hannan, R.; Saffery, R.; Shaw, M.L.; Williams, E., Choo, K.H.A. Centromere RNA is a key component for the assembly of nucleoproteins at the nucleolus and centromere. Genome Res., 2007, 17: 1146-1160.

[12] Fry, K.; Salser, W. Nucleotide sequences of HS- $\alpha$ satellite DNA from kangaroo rat Dipodomys ordii and characterisation of similar sequences in other rodents. Cell, 1977, 12: 1069-1084.

[13] Ugarković, Đ.; Plohl, M. Variation in satellite DNA profiles causes and effects. EMBO J., 2002, 21: 5955-5959.

[14] Meštrović, N.; Plohl, M.; Mravinac, B.; Ugarković, Đ. Evolution of satellite DNAs from the genus Palorus-experimental evidence for the "library" hypothesis. Mol. Biol. Evol., 1998, 15: 1062-1068.

[15] King, K.; Jobst, J.; Hemleben, V. Differential homogenisation and amplification of two satellite DNAs in the genus Cucurbita $(\mathrm{Cu}-$ curbitaceae). J. Mol. Evol., 1995, 4: 996-1005.

[16] Vershinin, A.V.; Alkhimova, E.G.; Heslop-Harrison, J.S. Molecular diversification of tandemly organised sequences and heterochromatic chromosome regions in some Triticeae species. Chromosome Res., 1996, 4: 517-525.

[17] Kawabe, A.; Charlesworth, D. Patterns of DNA variation among three centromere satellite families in Arabidopsis halleri and A. lyrata. J. Mol. Evol., 2007, 64: 237-247.

[18] Meštrović, N.; Castagnone-Sereno, P.; Plohl, M. Interplay of selective pressure and stochastic events directs evolution of the MEL172 satellite DNA library in root-knot nematodes. Mol. Biol. Evol., 2006, 23: 2316-2325.

[19] Cesari, M.; Luchetti, A.; Passamonti, M.; Scali, V.; Mantovani, B. Polymerase chain reaction amplification of the Bag320 satellite family reveals the ancestral library and past gene conversion events in Bacillus rossius (Insecta Phasmatodea). Gene, 2003, 312: 289295.

[20] Bruvo-Mađarić, B.; Plohl, M.; Ugarković, Đ. Wide distribution of related satellite DNA families within the genus Pimelia (Tenebrionidae). Genetica, 2007, 130: 35-42.

[21] Lin, C.C.; Li, Y.C. Chromosomal distribution and organization of three cervid satellite DNAs in Chinese water deer (Hydropotes inermis). Cytogenet. Genome Res., 2006, 114: 147-154.

[22] Bulazel, K.V.; Ferreri, G.C.; Eldridge, M.D.; O’ Neill, R.J. Species-specific shifts in centromere sequence composition are coincident with breakpoint reuse in karyotypically divergent lineages. Genome Biol., 2007, 8: R170.

[23] Nijman, I.J.; Lenstra, J.A. Mutation and recombination in cattle satellite DNA: a feedback model for the evolution of satellite DNA repeats. J. Mol. Evol., 2001, 52: 361-371.
[24] Lee, C.; Wevrick, R.; Fisher, R.B.; Ferguson-Smith, M.A.; Lin, C.C. Human centromeric DNAs. Hum. Genet., 1997, 100: 291-304.

[25] Alexandrov, I.; Kazakov, A.; Tumeneva, I.; Shepelev, V.; Yurov, Y. Alpha-satellite DNA of primates: old and new families. Chromosoma, 2001, 110: 253-266.

[26] Schueler, M.G.; Dunn, J.M.; Bird, C.P.; Ross, M.T.; Viggiano, L., NISC Comparative Sequencing Program, Rocchi, M., Willard, H.F., Green, E.D. Progressive proximal expansion of the primate X chromosome centromere. Proc. Natl. Acad. Sci. USA, 2005, 102: 10563-10568.

[27] Alkan, C.; Ventura, M.; Archidiacono, N.; Rocchi, M.; Sahinalp, S.C.; Eichler, E.E. Organization and evolution of primate centromeric DNA from whole-genome shotgun sequence data. PLoS Comput. Biol., 2007, 3: e181.

[28] Yoda, K.; Nakamura, T.; Masumoto, H.; Suzuki, N.; Kitagawa, K.; Nakano, M.; Shinjo, A.; Okazaki, T. Centromere protein B of african green monkey cells - gene structure, cellular expression, and centromeric localization. Mol. Cell Biol., 1996, 16: 5169-5177.

[29] Goldberg, I.G.; Sawhney, H.; Pluta, A.F.; Warburton, P.E.; Earnshaw, W.C. Suprising deficiency of CENP-B binding sites in african green monkey alpha-satellite DNA - implications for CENP-B function at centromeres. Mol. Cell Biol., 1996, 16: 5156-5168.

[30] Dover, G.A. Molecular drive in multigene families: how biological novelties arise, spread and are assimilated. Trends Genet., 1986, 2: 159-165.

[31] Mravinac, B.; Plohl, M.; Meštrović, N.; Ugarković, Đ. Sequence of PRAT satellite DNA "frozen" in some coleopteran species. J. Mol. Evol., 2002, 54: 774-783.

[32] Mravinac, B.; Plohl, M.; Ugarković, Đ. Preservation and high sequence conservation of satellite DNAs indicate functional constraints. J. Mol. Evol., 2005, 61: 542-550.

[33] Li, Y.X.; Kirby, M.L. Coordinated and conserved expression of alphoid repeat and alphoid repeat-tagged coding sequences. Dev. Dynamics, 2003, 228: 72-81.

[34] Ugarković, Đ. Functional elements residing within satellite DNAs. EMBO Rep., 2005, 6: 1035-1039.

[35] Malik, H.S.; Bayes, J.J. Genetic conflicts during meiosis and the evolutionary origins of centromere complexity. Biochem. Soc. Trans., 2006, 34: 569-73.

[36] Pons, J.; Petitpierre, E.; Juan, C. Evolutionary dynamics of satellite DNA family PIM357 in species of the genus Pimelia (Tenebrionidae, Coleoptera). Mol. Biol. Evol., 2002, 19: 1329-1340.

[37] Jarmuž, M.; Glotzbach, C.D.; Bailey, K.A.; Bandyopadhyay, R.; Shaffer, L.G. The evolution of satellite III DNA subfamilies among primates. Amer. J. Hum. Genet., 2007, 80: 495-501.

[38] Rudd, M.A.; Wray, G.A.; Willard, H.F. The evolutionary dynamics of $\alpha$-satellite. Genome Res., 2006, 16: 88-96.

[39] Cooper, J.L.; Henikoff, S. Adaptive evolution of the histone fold domain in centromeric histones. Mol. Biol. Evol., 2004, 21: 17121718.

[40] Hall, S.E.; Kettler, G.; Preuss, D. Centromere satellites from Arabidopsis populations: maintenance of conserved and variable domains. Genome Res., 2003, 13: 195-205.

[41] Martinez-Balbas, A.; Rodriguez-Campos, A.; Gracia-Ramirez, M. Sainz, J.; Carrera, P.; Aymami, J.; Azorin, F. Satellite DNAs contain sequences that induce curvature. Biochemistry, 1990, 29: 23422348.

[42] Fitzgerald, D.J.; Dryden, G.L.; Bronson, E.C.; Williams, J.S.; Anderson, J.N. Conserved patterns of bending in satellite and nucleosome positioning DNA. J. Biol. Chem., 1994, 269: 2130321314.

[43] Ugarković, Đ.; Plohl, M.; Lucijanić-Justić, V.; Borštnik, B. Detection of satellite DNA in Palorus ratzeburgii: Analysis of curvature profiles and comparison with Tenebrio molitor satellite DNA. Biochimie., 1992, 74: 1075-1082.

[44] Dawe, R.K.; Henikoff, S. Centromeres put epigenetics in the driver's seat. Trends. Biochem. Sci., 2006, 31: 662-669.

[45] Lee, H.R.; Zhang, W.; Langdon, T.; Jin, W.; Yan, H.; Cheng, Z.; Jiang, J. Chromatin immunoprecipitation cloning reveals rapid evolutionary patterns of centromeric DNA in Oryza species. Proc. Natl. Acad. Sci. USA, 2005, 102: 11793-117998.

[46] Stephan, W. Recombination and the evolution of satellite DNA. Genet. Res., 1986, 47: 167-174.

[47] Ma, J.; Jackson, S.A. Retrotransposon accumulation and satellite amplification mediated by segmental duplication facilitate centromere expansion in rice. Genome Res., 2006, 16: 251-259. 
[48] Pons, J.; Bruvo, B.; Petitpierre, E.; Plohl, M.; Ugarković, D.; Juan, C. Complex structural feature of satellite DNA sequences in the genus Pimelia (Coleoptera: Tenebrionidae): random differential amplification from a common "satellite DNA library". Heredity, 2004, 92: 418-427.

[49] Slamovits, C.H.; Cook, J.A.; Lessa, E.P.; Rossi, M.S. Recurrent amplifications and deletions of satellite DNA accompanied chromosomal diversification in South American tuco-tucos (genus Ctenomys, Rodentia: Octodontidae): a phylogenetic approach. Mol. Biol. Evol., 2001, 18: 1708-1719.

[50] Smith, P.G. Evolution of repeated sequences by unequal crossover. Science, 1976, 191: 528-535.

[51] Assum, G.; Fink, T.; Steinbeisser, T.; Fisel, K.J. Analysis of human extrachromosomal DNA elements originating from different betasatellite subfamilies. Hum. Genet., 1993, 91: 489-495.

[52] Feliciello, I; Picariello, O.; Chinali, G. Intra-specific variability and unusual organization of the repetitive units in a satellite DNA from
Rana dalmatina: molecular evidence of a new mechanism of DNA repair acting on satellite DNA. Gene, 2006, 383: 81-92.

[53] Vogt, P. Potential genetic functions of tandem repeated DNA sequence blocks in the human genome are based on a highly conserved "chromatin folding code". Hum. Genet., 1990, 84: 301-336.

[54] Harp, J.M.; Uberbacher, E.C.; Roberson, A.E.; Palmer, E.L.; Gewiess, A.; Bunick, G.J. X-ray diffraction analysis of crystals containing twofold symmetric nucleosome core particles. Acta Crystallogr. D, 1996, 52: 283-288.

[55] Luger, K.; Mader, A.W.; Richmond, R.K.; Sargent, D.F., Richmond, T.J. Crystal structure of the nucleosome core particle at 2.8angstrom resolution. Nature, 1997, 389: 251-260.

[56] Dalal, Y.; Furuyama, T.; Vermaak, D.; Henikoff, S. Structure, dynamics, and evolution of centromeric nucleosomes. Proc. Natl. Acad. Sci. USA, 2007, 104: 15974-15981.

(C) Đurđica Ugarković; Licensee Bentham Open.

This is an open access article distributed under the terms of the Creative Commons Attribution License (http://creativecommons.org/license/by/2.5/), which permits unrestrictive use, distribution, and reproduction in any medium, provided the original work is properly cited. 